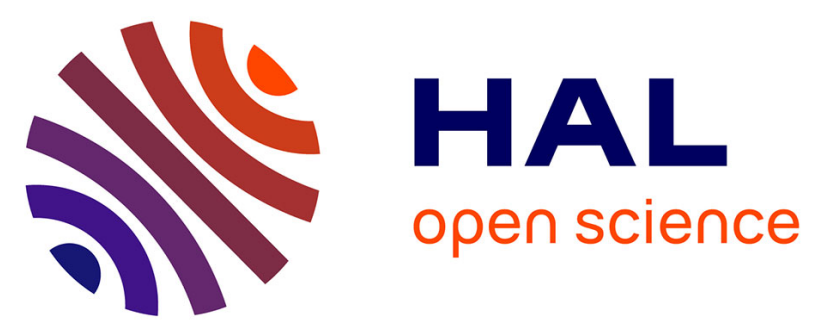

\title{
Changing use of noninvasive ventilation in critically ill patients: trends over 15 years in francophone countries
}

Alexandre Demoule, Sylvie Chevret, Annalisa Carlucci, Achille Kouatchet, Samir Jaber, Ferhat Meziani, Matthieu Schmidt, David Schnell, Céline Clergue, Jérôme Aboab, et al.

\section{To cite this version:}

Alexandre Demoule, Sylvie Chevret, Annalisa Carlucci, Achille Kouatchet, Samir Jaber, et al.. Changing use of noninvasive ventilation in critically ill patients: trends over 15 years in francophone countries. Intensive Care Medicine, 2016, 42 (1), pp.82 - 92. 10.1007/s00134-015-4087-4 . hal-01780694

\section{HAL Id: hal-01780694 \\ https://hal.umontpellier.fr/hal-01780694}

Submitted on 4 Dec 2019

HAL is a multi-disciplinary open access archive for the deposit and dissemination of scientific research documents, whether they are published or not. The documents may come from teaching and research institutions in France or abroad, or from public or private research centers.
L'archive ouverte pluridisciplinaire HAL, est destinée au dépôt et à la diffusion de documents scientifiques de niveau recherche, publiés ou non, émanant des établissements d'enseignement et de recherche français ou étrangers, des laboratoires publics ou privés. 
Alexandre Demoule

Sylvie Chevret

Annalisa Carlucci

Achille Kouatchet

Samir Jaber

Ferhat Meziani

Matthieu Schmidt

David Schnell

Céline Clergue

Jérôme Aboab

Antoine Rabbat

Béatrice Eon

Claude Guérin

Hugues Georges

Benjamin Zuber

Jean Dellamonica

Vincent Das

Joël Cousson

Didier Perez

Laurent Brochard

Elie Azoulay

oVNI Study Group
Changing use of noninvasive ventilation in critically ill patients: trends over 15 years in francophone countries
Take-home message: NIV use and success rates have increased over time. Use of NIV is associated with decreased mortality. Indications and modalities have also changed (pre-ICU and post-extubation NIV). In patients with de novo acute respiratory failure, NIV use has decreased and NIV failure is no longer associated with mortality, suggesting better patient selection.

A. Demoule $(\varangle) \cdot$ M. Schmidt Service de Pneumologie et Réanimation Médicale, Groupe Hospitalier PitiéSalpêtrière, Assistance Publique-Hopitaux de Paris, 47-83 boulevard de l'Hôpital, 75651 Paris Cedex 13, France e-mail: alexandre.demoule@psl.aphp.fr
A. Demoule - M. Schmidt UMR-S 1158, INSERM et Université Pierre et Marie Curie-Paris 6, Paris, France

S. Chevret

Département de biostatistique et d'Information médicale, et INSERM UMR717, Hôpital Saint-Louis, Paris, France

A. Carlucci

Respiratory Intensive Care Unit, IRCCS

Fondazione S. Maugeri, Pavia, Italy

A. Kouatchet

Réanimation médicale et Médecine hyperbare, Centre Hospitalier Universitaire, Angers, France

S. Jaber

Département d'Anesthésie et Réanimation, Hôpital Saint-Eloi, Montpellier, France

F. Meziani

Service de Réanimation Médicale, Nouvel Hôpital Civil, Hôpitaux Universitaires de Strasbourg, Strasbourg, France

D. Schnell · E. Azoulay

Service de Réanimation médicale, Hôpital

Saint-Louis, Paris, France
C. Clergue

Service Réanimation polyvalente, Centre Hospitalier Sud Francilien, Evry, France

J. Aboab

Service de Réanimation

Médicochirurgicale, Hôpital Raymond Poincaré, Garches, France

A. Rabbat

Service de Pneumologie et Soins Intensifs Respiratoires, Hôpital Cochin, Paris, France

B. Eon

UMR 7268 ADéS, Aix-Marseille

Université/Espace éthique méditerranéen, Réanimation des Urgences et MédicaleHôpital La Timone 2, Marseille, France

C. Guérin

Service de Réanimation médicale, Hôpital de la Croix Rousse, Lyon, France

H. Georges

Service de Réanimation Polyvalente et Maladies Infectieuses, Centre Hospitalier, Tourcoing, France

B. Zuber

Service de Réanimation Médicale, Hôpital Cochin, Paris, France 
J. Dellamonica

Service de Réanimation Médicale, Centre Hospitalier Universitaire de l'Archet, Nice, France

\section{Das}

Service de Réanimation Polyvalente, Centre Hospitalier André Grégoire, Montreuil,

France

\section{J. Cousson}

Service de Réanimation Polyvalente, Centre Hospitalier Universitaire Robert Debré,

Reims, France

D. Perez

Service de Réanimation Polyvalente, Centre Hospitalier Louis Pasteur, Dole, France

\section{Brochard}

Keenan Research Centre and Li Ka Shing Institute, Saint-Michael's Hospital, Toronto, ON, Canada

\section{Brochard}

Interdepartmental Division of Critical Care Medicine, University of Toronto, Toronto, Canada
Abstract Purpose: Over the last two decades, noninvasive ventilation (NIV) has been proposed in various causes of acute respiratory failure (ARF) but some indications are debated. Current trends in NIV use are unknown. Methods: Comparison of three multicenter prospective audits including all patients receiving mechanical ventilation and conducted in 1997, 2002, and 2011 in francophone countries. Results: Among the 4132 patients enrolled, 2094 (51\%) required ventilatory support for ARF and 2038 (49\%) for nonrespiratory conditions. Overall NIV use was markedly increased in 2010/11 compared to 1997 and 2002 (37\% of mechanically ventilated patients vs. $16 \%$ and $28 \%$, $P<0.05)$. In 2010/11, the use of first-line NIV for ARF had reached a plateau (24\% vs. $16 \%$ and $23 \%$, $P<0.05)$ whereas pre-ICU and postextubation NIV had substantially increased (11\% vs. $4 \%$ and $11 \%$ vs. $7 \%$, respectively, $P<0.05)$. First- line NIV remained stable in acute-onchronic RF, continued to increase in cardiogenic pulmonary edema, but decreased in de novo ARF $(16 \%$ in $2010 / 11$ vs. $23 \%$ in $2002, P<0.05$ ). The NIV success rate increased from $56 \%$ in 2002 to $70 \%$ in $2010 / 11$ and remained the lowest in de novo ARF. NIV failure in de novo ARF was associated with increased mortality in 2002 but not in 2010/11. Mortality decreased over time, and overall, NIV use was associated with a lower mortality. Conclusion: Increases in NIV use and success rate, an overall decrease in mortality, and a decrease of the adverse impact NIV failure has in de novo ARF suggest better patient selection and greater proficiency of staff in administering NIV. Trial registration: Clinicaltrials.gov Identifier NCT01449331.

Keywords Acute respiratory failure Mechanical ventilation.

Non-invasive ventilation . Outcome

\section{Introduction}

Over the last two decades, noninvasive ventilation (NIV) has become a cornerstone for the supportive therapy of acute respiratory failure (ARF) requiring intensive care unit (ICU) admission, particularly in COPD exacerbation and cardiogenic pulmonary edema. NIV has been proven to decrease the risks of endotracheal intubation and death in specific situations including acute-on-chronic respiratory failure $[1,2]$, acute cardiogenic pulmonary edema [3], and de novo respiratory failure in immunocompromised patients $[4,5]$. To determine whether the benefits observed in clinical trials also occurred in everyday practice, we conducted two prospective audits in French ICUs in 1997 [6] and 2002 [7]. The audits showed an increase in NIV use, both overall and in specific patient populations. Adjusted analysis comparing intubated and NIV patients indicated clear benefits for patients with acute-on-chronic respiratory failure or cardiogenic pulmonary edema, but suggested higher mortality in immunocompetent patients with de novo ARF intubated after NIV failure [7].
Since our last survey, several studies by various groups worldwide have further documented new indications and possible benefits of NIV and established the usefulness of this intervention in the emergency room [8, 9] and after extubation [10], including in postoperative patients [11, 12]. In 2006, a consensus conference panel recommended using NIV only in situations for which a high level of evidence supported beneficial effects [13]. International studies have shown an increase in the use of NIV over time $[14,15]$. Whether current clinical practice reflects these research findings and recommendations is, however, unclear.

We designed a new prospective audit and a comparative study to compare NIV use in terms of both frequency and indications with previous surveys and to assess the effects of NIV on ICU survival. In this study, we thus combined data from a new observational cohort study of patients with ARF and data from our two previous studies on NIV using a similar methodology in order to get trends in use and results over a 15-year period $[6,7]$. Some of these data have been previously reported in the form of abstracts [16]. 


\section{Patients and methods}

Study centers

We conducted a prospective observational study in 54 French and Belgian ICUs (Table E1), including 43 (80\%) belonging to the REVA (Research Network in Mechanical Ventilation) or FAMIREA (to improve the effectiveness of communication with the relatives of ICU patients) network. Each center included consecutive adults who required ventilatory assistance over a 2-month period between November 2010 and April 2011. Another study from this cohort has been published elsewhere [17]. The present study has only marginal overlap (less than $1 \%$ ) with the Schnell et al. study [18].

The study was approved by the institutional review board of the French-language Society for Respiratory Medicine (Société de Pneumologie de Langue Française). Written informed consent was obtained from all patients and relatives.

Patients

For the new survey, performed over a 2-month period between November 2010 and April 2011, we used the same methodology as in our two previous studies $[6,7]$. Participating ICUs prospectively included consecutive adults who required endotracheal or noninvasive ventilation for ARF at any time during the ICU stay over a 4-week enrollment period and patients were followed until ICU discharge.

Each day, the study investigator completed a standardized electronic case report form, recording data from ICU admission to ICU discharge. Demographic data and history consisted of age, gender, Simplified Acute Physiologic Score (SAPS) II [19], underlying diseases such as a history of chronic obstructive pulmonary disease (COPD) or other causes of chronic respiratory failure (i.e., restrictive, obesity, neuromuscular), and the need for home oxygen therapy or NIV, chronic heart failure (NYHA III or IV), and immunosuppression (defined as neutropenia below $1000 / \mathrm{mm}^{3}$, malignancy with anticancer chemotherapy, immunosuppressive therapy for solid organ transplantation, corticosteroid therapy of $20 \mathrm{mg}$ or more per day for at least 3 weeks, or AIDS). Patients were classified as endotracheal intubation (ETI) for either a non-respiratory cause (coma, postoperative management, other) or ARF. The precipitating factor of ARF was either an acute-on-chronic respiratory failure defined as a respiratory failure occurring in a patient with a preexisting respiratory disease (COPD or restrictive such as obesity hypoventilation syndrome or neuromuscular disease), a cardiogenic pulmonary edema, or a de novo ARF defined as a respiratory failure not exacerbating a chronic lung or cardiac insufficiency, also called hypoxemic ARF. Main physiological data (respiratory rate, heart rate, and systolic arterial blood pressure) and arterial blood gas values before initiation of ventilatory support were recorded on admission.

The following parameters were recorded daily in patients receiving NIV: physiological data, available arterial blood gas values under NIV, and the characteristics of noninvasive ventilatory support, including duration of NIV (prescribed and effective), type of ventilator (ICU-type, NIV ventilator defined as a ventilator specifically designed for in-hospital NIV, and home device defined as a ventilator devoted to home ventilation), mode of ventilation, whether a NIV mode was used, main ventilator settings, type of mask (facial, nasal, integral mask, or helmet). The tolerance of NIV was also recorded daily by caregivers (scored from 1, very good tolerance to 4 , very poor tolerance; a score of 1 or 2 was considered as a good tolerance) and the extent of air leaks during NIV sessions (scored from 1, very small or none to 4, massive; a score of 3 or 4 was considered as a high level of leaks). The need for invasive mechanical ventilation, ICU mortality, and length of stay were recorded. Treatment-limitation decisions were classified into two groups according to NIV goals [20]: do-not-intubate (DNI) decision and NIV for comfort care only. The patients who received ETI or who died in the $24 \mathrm{~h}$ following NIV discontinuation were classified as NIV failure. The patients treated with NIV until they no longer required assistance were classified as NIV success.

\section{Data quality}

Inconsistencies in the data entered by the investigators were resolved by an ICU physician not involved in the study and who compared the study case report forms with the medical charts. The database was audited by means of an independent check of all ICU variables on a random sample of $10 \%$ of patients.

\section{Statistical analysis}

The median and interquartile range (IQR) were calculated for continuous variables and the absolute and relative frequencies for categorical variables, together with the $95 \%$ confidence intervals $(95 \% \mathrm{CI})$ where appropriate. We compared the data from 2010/11 with those from the 1997 and 2002 studies [6, 7]. The Mann-Whitney $U$ test or Kruskal-Wallis test was chosen for continuous data, as appropriate, and the Chi square test or Fisher exact test for categorical variables.

Univariate analyses were performed to assess factors potentially associated with NIV failure. This analysis was restricted to first-line NIV patients defined as those who received NIV as the first-line ventilation modality in the 
ICU, and patients who received comfort-only NIV were excluded. Factors associated with NIV failure at the $5 \%$ level were entered into a multivariate logistic regression model.

To assess the possible impact of NIV use, NIV success, and NIV failure on hospital mortality rates, we confined this analysis to patients with ARF. The primary endpoint of this analysis was survival to ICU discharge and we therefore excluded DNI patients since NIV failure is strongly associated with mortality in DNI patients. We classified patients into two subgroups: de novo ARF on the one hand and either acute-on-chronic respiratory failure or cardiogenic pulmonary edema on the other hand. To assess NIV success and NIV failure, we considered that invasive mechanical ventilation was the reference category [adjusted odds ratio (aOR), 1.00].

$P$ values less than 0.05 were considered significant. All tests were two-tailed. Statistical tests were performed using SPSS 18 software (IBM, Armonk, NY).

\section{Results}

Table 1 displays the main characteristics of the participating ICUs and causes of ARF. Of 4132 enrolled patients, 2094 (51\%; $95 \%$ CI 50-52) required ventilatory support for ARF and 2038 (49\%; $95 \%$ CI 48-50) for non-respiratory conditions. Figure 1 displays the flow chart of the study. Twenty-eight ICUs participated in the 1997 and 2002 studies, 34 in the 2002 and 2010/11 studies, and 19 participated in all three studies.

\section{NIV use}

NIV was the first-line ventilation modality in $24 \%(95 \%$ CI 22-26) of patients in 2010/11, a proportion similar to that observed in 2002 and higher than that in 1997 $(P<0.05)$. In 2010/11, $11 \%$ (95\% CI 10-12) of patients received NIV before ICU admission (outside the hospital, in the emergency room, or in a ward (Fig. 2; Table E2); this proportion was significantly higher than in 2002 and $1997(P<0.05)$. NIV was used after extubation in $11 \%$ (95\% CI 10-12) of patients, a significant increase compared to $2002(P<0.05)$; in this situation, NIV was more often delivered preventively in high-risk patients $(64 \%)$ than to treat ARF (36\%).

The proportion of patients who received NIV before ICU admission, as first-line treatment in the ICU, or after extubation was $37 \%$ (95\% CI 35.0-39), which was significantly higher than in 2002 and $1997(P<0.05)$.

Compared to 1997 and 2002, 2010/11 differed regarding the causes of ARF treated with NIV (Fig. 3; Table E2). In acute-on-chronic ARF, NIV use increased between 1997 and $2002(P<0.05)$ but not further in

Table 1 Main characteristics of participating intensive care units in the three prospective audits and reasons for ventilatory support

\begin{tabular}{|c|c|c|c|c|}
\hline & 1997 & 2002 & 2010/11 & $p$ \\
\hline Participating units & 42 & 70 & 54 & \\
\hline University hospital & $31(74)$ & $38(54)$ & $34(62)$ & 0.11 \\
\hline \multicolumn{5}{|l|}{ ICU type } \\
\hline Medical & $23(55)$ & $28(40)$ & $29(54)$ & 0.19 \\
\hline Medical-surgical & $19(45)$ & $42(60)$ & $25(46)$ & \\
\hline Number of ICU beds & $12(10-14)$ & $11(8-14)$ & $13(10-18)^{\$}$ & 0.001 \\
\hline Number of step-up/down unit beds integrated to the ICU & $0(0-2)$ & $0(0-0)$ & $6(2-10)^{*} \$$ & 0.001 \\
\hline Number of admissions/year & $580(450-750)$ & $458(350-618)$ & $600(472-890)^{\$}$ & 0.001 \\
\hline Number of patients receiving MV/year & $290(214-382)$ & $240(180-313)$ & $373(280-483)^{\$}$ & $<0.0001$ \\
\hline Number of attending physicians and fellows & $4(3-5)$ & $4(3-4)$ & $6(5-7)^{*}, \$$ & $<0.0001$ \\
\hline Number of residents & $3(1-3)$ & $2(0-3)$ & $4(2-5)^{\$}$ & $<0.0001$ \\
\hline Total number of patients included & $n=689$ & $n=1076$ & $n=2367$ & \\
\hline MV for acute respiratory failure & $361(52)$ & $588(55)$ & $1145(48)^{\$}$ & 0.002 \\
\hline Acute-on-chronic respiratory failure & $85(12)$ & $167(16)$ & $467(20)^{*}, \$$ & $<0.0001$ \\
\hline COPD & $63(9)$ & $114(11)$ & $320(14)$ & \\
\hline Restrictive disease & $22(3)$ & $46(4)$ & $147(6)$ & \\
\hline Acute cardiogenic pulmonary edema & $49(7)$ & $84(8)$ & $140(6)$ & 0.09 \\
\hline De novo acute respiratory failure & $227(33)$ & $337(31)$ & $538(23)^{*} \$$ & $<0.0001$ \\
\hline Pneumonia & 95 (14) & $163(15)$ & $360(15)$ & \\
\hline Extrapulmonary sepsis & $49(7)$ & $65(6)$ & $62(3)$ & \\
\hline Other & 93 (12) & $109(10)$ & $116(5)$ & \\
\hline MV for a non-respiratory cause & $328(48)$ & $488(45)$ & $1222(52)^{\$}$ & 0.002 \\
\hline Coma & $201(29)$ & $358(33)$ & $719(30)$ & \\
\hline Postoperative management & $103(15)$ & $130(12)$ & $240(10)$ & \\
\hline Other & $24(3)$ & & $263(11)$ & \\
\hline
\end{tabular}

Continuous variables are expressed as median (interquartile range) and categorical variables as absolute value (\%) 
Fig. 1 Flow chart of the study. NIV noninvasive ventilation, $I C U$ intensive care unit, $D N I$ do-not-intubate

4132 patients needed ventilatory support

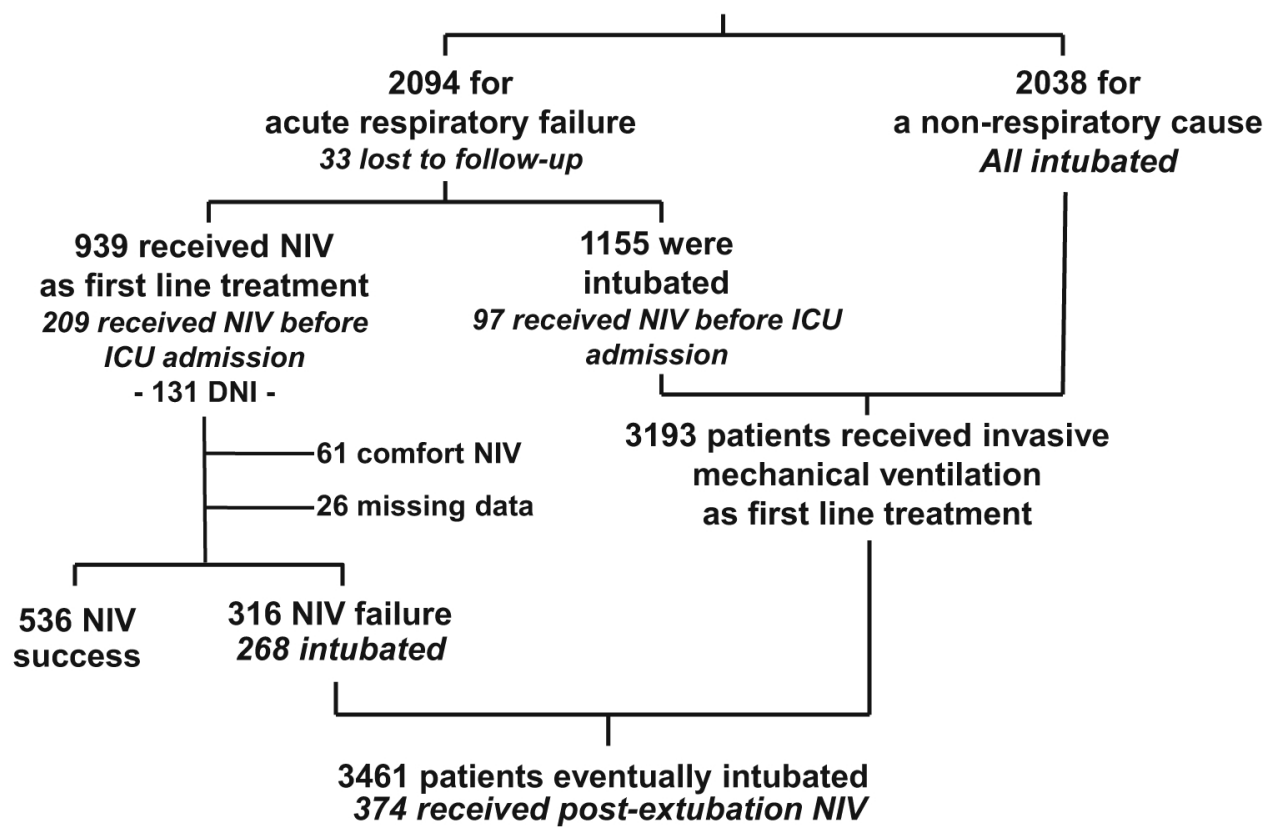

3461 patients eventually intubated 374 received post-extubation NIV

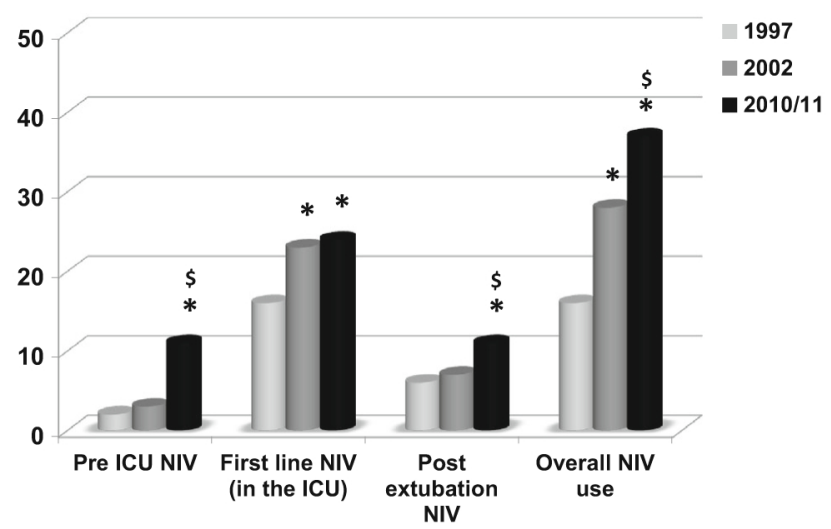

Fig. 2 Changes in the use of noninvasive ventilation across the three study periods. NIV noninvasive ventilation; pre-intensive care unit (ICU) NIV is NIV given before ICU admission, in the ambulance, emergency room, or ward. ${ }^{*} P<0.05$ compared to $1997,{ }^{\$} P<0.05$ compared to 2002

2010/11. In patients with cardiogenic pulmonary edema, NIV was used significantly more often in 2010/11 than in 2002 and $1997(P<0.05)$. Lastly, in de novo ARF, NIV use increased significantly between 1997 and 2002 but then decreased significantly from 2002 to 2010/11 $(P<0.05)$.

Patient and NIV characteristics

This analysis excluded the 61 patients who received comfort-only NIV in the ICU [21] and 26 patients with

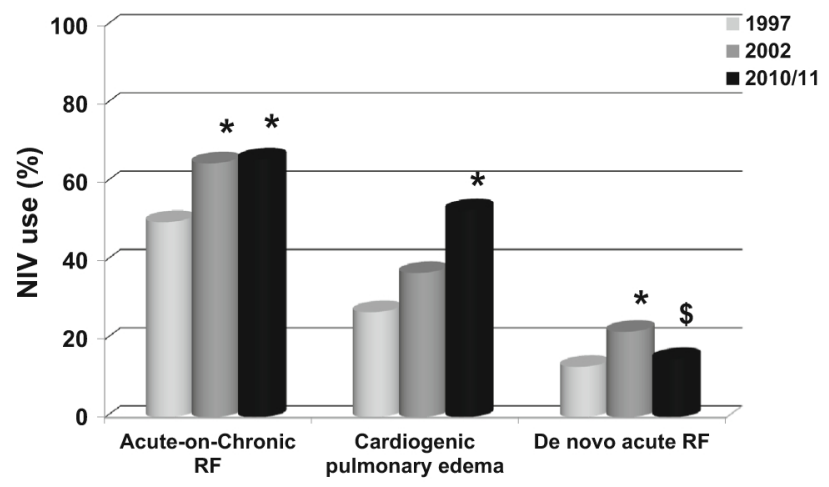

Fig. 3 Changes in the use of noninvasive ventilation according to the cause of acute respiratory failure. ${ }^{*} P<0.05$ compared to 1997 , ${ }^{\$} P<0.05$ compared to 2002

missing data on ICU characteristics (Fig. 1). Compared to the earlier studies, we found higher proportions of immunocompromised patients and of patients with DNI (Table 2). Illness severity at ICU admission remained unchanged over time. The use of NIV-dedicated ventilators has increased, use of home ventilators decreased, and ICU ventilators remained the most widely used devices (with NIV algorithm use in $78 \%$ of patients). Pressure support was the most widely prescribed mode and has increased, whereas continuous positive airway pressure use decreased. The frequency of face mask use was unchanged; full-face masks were used more often and nasal masks less often. The average tolerance of NIV remained similar, whereas estimated leak levels diminished. 
Table 2 Characteristics of first-line noninvasive ventilation episodes $(n=855)$

\begin{tabular}{|c|c|c|c|c|}
\hline & $1997(n=108)$ & $2002(n=248)$ & $2010 / 11(n=499)$ & $P$ value \\
\hline \multicolumn{5}{|l|}{ Patient characteristics } \\
\hline Male, $n(\%)$ & $67(62)$ & $158(64)$ & $319(64)$ & 0.968 \\
\hline Age (years) & $67(54-74)$ & $71(59-77)$ & $69(59-78)$ & 0.081 \\
\hline $\mathrm{BMI}\left(\mathrm{kg} \mathrm{m}^{-2}\right)$ & ND & $25(22-29)$ & $26(22-32)$ & 0.097 \\
\hline Chronic cardiac disease, $n(\%)$ & $19(18)$ & $63(25)$ & $105(21)$ & 0.086 \\
\hline Chronic respiratory disease, $n(\%)$ & $58(54)$ & $147(59)$ & $300(60)$ & 0.42 \\
\hline Immunosuppression, $n(\%)$ & $21(19)$ & $40(16)$ & $131(26)^{\$}$ & 0.002 \\
\hline DNI, $n(\%)$ & ND & $33(13)$ & $98(20)^{\$}$ & $<0.0001$ \\
\hline SAPS II & $32(23-43)$ & $37(30-46)^{*}$ & $35(27-45)$ & 0.007 \\
\hline \multicolumn{5}{|l|}{ NIV episode } \\
\hline \multicolumn{5}{|l|}{ Prior to NIV initiation } \\
\hline Respiratory rate/min & $30(25-35)$ & $30(24-35)$ & $31(25-36)^{\$}$ & 0.002 \\
\hline \multicolumn{5}{|l|}{ Blood gases } \\
\hline $\mathrm{PaO}_{2} / \mathrm{FiO}_{2}(\mathrm{mmHg})$ & $217(165-263)$ & $211(166-263)$ & $216(160-280)$ & 0.845 \\
\hline $\mathrm{PaCO}_{2}(\mathrm{mmHg})$ & $51(37-75)$ & $55(37-76)$ & $52(39-70)$ & 0.784 \\
\hline $\mathrm{pH}$ & $7.34(7.27-7.42)$ & $7.34(7.24-7.41)$ & $7.34(7.27-7.41)$ & 0.393 \\
\hline \multicolumn{5}{|l|}{ At NIV initiation } \\
\hline \multicolumn{5}{|l|}{ Ventilator, $n(\%)$} \\
\hline ICU ventilator & 77 (73) & $178(72)$ & $238(82)$ & 0.12 \\
\hline NIV-dedicated & $8(7)$ & $27(11)$ & $51(18)^{*}$ & 0.02 \\
\hline Home ventilator & $3(3)$ & $11(4)$ & $2^{\$}$ & 0.015 \\
\hline CPAP-dedicated & $16(15)$ & $19(8)^{*}$ & $0 *, \$$ & $<0.0001$ \\
\hline \multicolumn{5}{|l|}{ Mode, $n(\%)$} \\
\hline Pressure support & $69(64)$ & $207(83)^{*}$ & $187 / 222(84)^{*}$ & $<0.0001$ \\
\hline Assist control & $16(15)$ & $18(7)^{*}$ & $35 / 222(14)^{\$}$ & $<0.0001$ \\
\hline CPAP & $20(19)$ & $19(8) *$ & $0 *, \$$ & $<0.0001$ \\
\hline NIV mode, $n(\%)$ & ND & ND & $430(86)$ & \\
\hline \multicolumn{5}{|l|}{ Mask, $n(\%)$} \\
\hline Face & $95(88)$ & $205(83)$ & $411(82)$ & 0.243 \\
\hline Full-face & 0 & $22(9)^{*}$ & $84(17)^{*, \$}$ & $<0.0001$ \\
\hline Nasal & $10(9)$ & $14(6)$ & $5(1)^{* \$ \$}$ & $<0.0001$ \\
\hline Good NIV tolerance, $n(\%)$ & $86(80)$ & $202(81)$ & $397(80)$ & 0.894 \\
\hline High level of leaks, $n(\%)$ & 18 (17) & $15(6)^{*}$ & $29(6)^{*}$ & 0.001 \\
\hline \multicolumn{5}{|l|}{ Blood gases on NIV } \\
\hline $\mathrm{PaO}_{2} / \mathrm{FiO}_{2}(\mathrm{mmHg})$ & $204(144-260)$ & $219(149-288)$ & $213(161-256)$ & 0.846 \\
\hline $\mathrm{PaCO}_{2}(\mathrm{mmHg})$ & $54(41-71)$ & $49(38-71)$ & $53(40-66)$ & 0.789 \\
\hline $\mathrm{pH}$ & $7.37(7.30-7.41)$ & $7.36(7.30-7.42)$ & $7.36(7.29-7.40)$ & 0.341 \\
\hline NIV success, $n(\%)$ & $65(60)$ & $139(56)$ & $348(70)^{\$}$ & $<0.0001$ \\
\hline Duration of NIV (days) & $3(1-5)$ & $3(2-5)$ & $2(1-5)$ & 0.590 \\
\hline
\end{tabular}

Continuous variables are expressed as median (interquartile range) and categorical variables as absolute value (\%)

$B M I$ body mass index, $N D$ not determined, $D N I$ do-not-intubate order, SAPS Simplified Acute Physiology Score, NIV noninvasive ventilation, $C P A P$ continuous positive airway pressure

Factors associated with NIV outcome

This analysis excluded the 61 patients who received comfort-only NIV in the ICU [21] and 26 patients with missing data on either ICU characteristics or NIV success (Fig. 1). The NIV success rate was significantly higher in 2010/11 than in 2002 and 1997 (Table 2). Table 3 shows the factors associated with NIV success identified by univariate analysis. By multivariate logistic regression analysis, six of these factors independently predicted the result of NIV. Three factors were associated with NIV success: receiving NIV in 2010/11 (OR 2.02; 95 \% CI 1.39-2.93; $P<0.0001$ ), $\mathrm{PaO}_{2} / \mathrm{FiO}_{2}$ ratio (per $25 \mathrm{mmHg}$, OR 25.075; $95 \%$ CI 25.025-25.125; $P=0.004)$, and good NIV tolerance as defined by ICU nurses (OR 2.76;
$* P<0.05$ vs. $1997 ;{ }^{\$} P<0.05$ vs. 2002

$95 \%$ CI $1.71-4.43 ; P<0.0001)$. Three factors were associated with NIV failure: SAPS II (OR per point 0.94; $95 \%$ CI 0.93-0.96; $P<0.0001$ ), high level of leaks (OR $0.39 ; 95 \%$ CI $0.19-0.81 ; P=0.012$ ), de novo ARF (OR $0.47 ; 95 \%$ CI $0.32-0.48 ; P<0.0001)$.

\section{Associations between NIV use and mortality}

This analysis was restricted to patients with ARF. The patients who received comfort-only NIV in the ICU, the DNI patients, and those with missing data or lost to follow-up were excluded (Fig. 1). Crude ICU mortality was lower in 2010/11 than in the earlier studies (Table 4). This decrease was observed in the overall population, in 
Table 3 Univariate analysis: factors associated with failure of noninvasive ventilation for first-line episodes $(n=852)$

\begin{tabular}{|c|c|c|c|}
\hline & NIV failure $(n=316)$ & NIV success $(n=536)$ & $P$ value \\
\hline \multicolumn{4}{|l|}{ Study year } \\
\hline 1997, n(\%) & $51(16)$ & $54(10)$ & \multirow[t]{3}{*}{$<0.0001$} \\
\hline $2002, n(\%)$ & $109(34)$ & $139(26)$ & \\
\hline $2010 / 11, n(\%)$ & $156(49)$ & $343(64)$ & \\
\hline Chronic respiratory disease, $n(\%)$ & $159(50)$ & $345(64)$ & 0.002 \\
\hline \multicolumn{4}{|l|}{ Cause of ARF } \\
\hline Acute-on-chronic ARF, $n(\%)$ & $116(37)$ & $323(60)$ & $<0.0001$ \\
\hline Acute cardiogenic pulmonary edema, $n(\%)$ & $46(15)$ & $76(14)$ & 0.87 \\
\hline De novo ARF, $n(\%)$ & $152(48)$ & $134(25)$ & $<0.0001$ \\
\hline \multicolumn{4}{|l|}{ NIV episode } \\
\hline \multicolumn{4}{|l|}{ At ICU admission } \\
\hline SAPS II & $42(33-54)$ & $32(26-40)$ & $<0.0001$ \\
\hline \multicolumn{4}{|l|}{ Blood gases prior to NIV } \\
\hline $\mathrm{PaO}_{2} / \mathrm{FiO}_{2}(\mathrm{mmHg})$ & $194(132-256)$ & $226(177-280)$ & 0.0001 \\
\hline $\mathrm{PaCO}_{2}(\mathrm{mmHg})$ & $47(35-70)$ & $56(41-72)$ & 0.0001 \\
\hline \multicolumn{4}{|l|}{ At NIV start } \\
\hline Good NIV tolerance, $n(\%)$ & $219(69)$ & $454(85)$ & $<0.0001$ \\
\hline High level of leaks, $n(\%)$ & $33(56)$ & $25(42)$ & $<0.0001$ \\
\hline \multicolumn{4}{|l|}{ Blood gases under NIV } \\
\hline $\mathrm{PaO}_{2} / \mathrm{FiO}_{2}(\mathrm{mmHg})$ & $171(117-235)$ & $237(185-297)$ & $<0.0001$ \\
\hline $\mathrm{PaCO}_{2}(\mathrm{mmHg})$ & $47(35-68)$ & $55(43-69)$ & 0.026 \\
\hline $\mathrm{pH}$ & $7.35(7.25-7.42)$ & $7.37(7.31-7.41)$ & 0.028 \\
\hline Duration of NIV (days) & $2(1-4)$ & $3(3-5)$ & $<0.0001$ \\
\hline DNI, $n(\%)$ & $62(20)$ & $69(13)$ & $<0.0001$ \\
\hline
\end{tabular}

Continuous variables are expressed as median (interquartile range) and categorical variables as absolute value (\%)

NIV noninvasive ventilation, ARF acute respiratory failure, ICU intensive care unit, SAPS Simplified Acute Physiology Score, DNI donot-intubate order

the patients given first-line NIV (including those who failed NIV), and in those who received first-line endotracheal intubation. Mortality decreased for all causes of ARF but the decrease was larger in patients with de novo ARF than in those with other causes of ARF.

In this cohort of 1843 patients, two factors were independently associated with lower mortality: NIV (OR $0.68 ; 95 \%$ CI $0.51-0.90 ; P=0.007)$ and admission in 2010/11 (OR 0.39; $95 \%$ CI 0.28-0.55; $P<0.0001$ ). Three factors were independently associated with higher mortality: higher SAPS II (OR per point, 1.05; $95 \%$ CI 1.04-1.06; $P<0.0001$ ), immunosuppression (OR 2.11; $95 \%$ CI 1.60-2.77; $P<0.0001$ ), and de novo ARF (OR $1.73 ; 95 \%$ CI $1.34-2.24 ; P<0.0001)$.

Duration of mechanical ventilation and ICU length of stay were shorter in 2010/11 than in 1997 and 2002.

Impact of NIV use and failure on survival according to the cause of ARF and time period

Considering all intubated and NIV patients with acute-onchronic respiratory failure or cardiogenic pulmonary edema from the three prospective audits in a multivariate analysis, NIV use was associated with lower mortality (OR 0.36; $95 \%$ CI $0.23-0.57 ; P<0.0001$ ); NIV failure was not associated with higher mortality (OR $1.26 ; 95 \%$ CI $0.77-2.08 ; \quad P=0.36$ ) and this was consistent throughout the three prospective audits.
In patients with de novo ARF, impact of NIV use and failure was different. Indeed, NIV use was not associated with a better survival in the analysis of pooled data. When the three prospective audits were analyzed separately, we found an inconsistent effect over time of the impact of NIV failure on survival. NIV failure was indeed associated with a higher mortality in 1997 and in 2002 (OR 3.39; $95 \%$ CI $1.88-6.11 ; P<0.0001)$ but not anymore in 2010/11.

\section{Discussion}

Our study of NIV use in everyday clinical practice in a large number of ICUs over 15 years has three main findings. First, we found an increase in the overall use of NIV over time as well as changes in the distribution of NIV indication. Noticeably, pre-ICU and post-extubation NIV have substantially increased. We also found changes in the distribution of ARF causes treated with NIV. In particular, NIV was less often used to treat de novo ARF. Second, NIV success rates increased over time. Third, in patients with de novo ARF, NIV failure remained more common than in other causes of ARF but was no longer associated with mortality in 2010/11, in contrast to our previous findings in 1997 and 2002.

The significant increase in overall NIV use over time is consistent with other retrospective and prospective cohort studies $[15,22,23]$. Importantly, however, NIV 
Table 4 Comparisons of mortality, duration of mechanical ventilation, and length of intensive care unit stay

\begin{tabular}{|c|c|c|c|c|}
\hline & $\begin{array}{l}1997 \\
(n=356)\end{array}$ & $\begin{array}{l}2002 \\
(n=526)\end{array}$ & $\begin{array}{l}2010 / 11 \\
(n=961)\end{array}$ & $P$ value \\
\hline Overall ICU mortality, $n(\%)$ & $130 / 356(37)$ & $170 / 526(32)^{*}$ & $203 / 961(21)^{*, \$}$ & $<0.0001$ \\
\hline In first-line NIV & 23/107 (21) & $50 / 215(23)$ & $34 / 399(9)^{*, \$}$ & $<0.0001$ \\
\hline In first-line NIV success & $1 / 55(2)$ & $0 / 123(0)$ & 4/293 (1) & 0.463 \\
\hline In first-line NIV failure & $22 / 52(37)$ & $50 / 92(54)$ & $30 / 106(28)^{\$}$ & 0.002 \\
\hline In first-line invasive mechanical ventilation & $107 / 243(44)$ & $120 / 311(39)$ & $169 / 562(30)^{*}, \$$ & $<0.0001$ \\
\hline ICU mortality in de novo ARF, $n(\%)$ & $93 / 208(45)$ & $124 / 300(41)$ & $135 / 482(28)^{*, \$}$ & $<0.0001$ \\
\hline In first-line NIV & $16 / 45(36)$ & $37 / 91(41)$ & $19 / 121(16)^{*} \$$ & $<0.0001$ \\
\hline In first-line NIV success & $1 / 22(1)$ & $0 / 37(0)$ & $2 / 68(3)$ & 0.497 \\
\hline In first-line NIV failure & $15 / 22(70)$ & $37 / 54(70)$ & $17 / 53(32)^{*, \$}$ & $<0.0001$ \\
\hline In first-line invasive mechanical ventilation & $77 / 163(47)$ & $87 / 209(42)$ & $116 / 361(32)^{*} \$$ & $<0.0001$ \\
\hline $\begin{array}{l}\text { ICU mortality in acute-on-chronic ARF and acute } \\
\text { cardiogenic pulmonary edema, } n(\%)\end{array}$ & $33 / 134(25)$ & $46 / 226(20)$ & $144 / 828(17)^{* \$}$ & 0.004 \\
\hline In first-line NIV & $7 / 61(11)$ & $13 / 124(10)$ & $14 / 275(5)^{*, \$}$ & 0.017 \\
\hline In first-line NIV success & $0 / 31(0)$ & $0 / 86(0)$ & $2 / 222(1)$ & 0.591 \\
\hline In first-line NIV failure & $7 / 30(23)$ & $13 / 38(34)$ & $12 / 51(24)$ & 0.351 \\
\hline In first-line invasive mechanical ventilation & $26 / 73(36)$ & $33 / 102(32)$ & $51 / 193(26)$ & 0.280 \\
\hline \multicolumn{5}{|l|}{ Duration of mechanical ventilation (days) } \\
\hline All patients & $6(3-12)$ & $6(3-13)$ & $5(2-11)^{\$}$ & 0.005 \\
\hline First-line NIV & $5(2-11)$ & $5(2-12)$ & $3(2-6) *, \$$ & $<0.001$ \\
\hline First-line NIV success & $5(2-7)$ & $3(2-5)$ & $2(1-4) * \$$ & $<0.001$ \\
\hline First-line NIV failure & $9(3-21)$ & $11(5-19)$ & $8(5-15)$ & 0.172 \\
\hline First-line invasive mechanical ventilation & $6(3-13)$ & $7(3-16)$ & $7(3-15)$ & 0.446 \\
\hline \multicolumn{5}{|l|}{ ICU length of stay } \\
\hline All patients & $9(4-18)$ & $8(4-18)$ & $7(4-15)^{*}$ & 0.005 \\
\hline First-line NIV & $9(5-18)$ & $7(4-15)$ & $5(3-9) * \$$ & $<0.001$ \\
\hline First-line NIV success & $8(5-13)$ & $5(3-8) *$ & $4(2-6)^{*}, \$$ & $<0.001$ \\
\hline First-line NIV failure & $13(4-26)$ & $14(6-23)$ & $12(7-22)$ & 0.890 \\
\hline First-line invasive mechanical ventilation & $10(4-18)$ & $10(5-20)$ & $11(5-19)$ & 0.512 \\
\hline
\end{tabular}

Continuous variables are expressed as median (interquartile range) and categorical variables as absolute value (\%)

$N I V$ noninvasive ventilation, ICU intensive care unit

$* P<0.05$ vs. $1997 ;{ }^{\$} P<0.05$ vs. 2002

use did not increase to the same degree for each of the main indications. Significant increases occurred in NIV use before ICU admission (during out-of-hospital care, in the emergency room, and in the wards) and after extubation. These results illustrate the implementation in everyday practice of the results of studies showing possible benefits of NIV delivered in the emergency room [8, 9, 24-27] or to prevent ARF after extubation (the indication for $64 \%$ of our patients receiving NIV after extubation). There was no increase in first-line NIV between 2002 and 2010/11. However, the distribution of ARF causes treated with first-line NIV changed. NIV was less often used to treat de novo ARF, in keeping with studies suggesting a possible harmful effect of NIV in this indication $[18,28]$. Consensus panels have concluded that the use of NIV in de novo ARF is controversial [29]. In acute-on-chronic respiratory failure, NIV use did not increase between 2002 and 2010/11, suggesting a need for further efforts to promote NIV in this indication. A recent study conducted in Austria showed an increase in NIV treatment of patients with acute-on-chronic respiratory failure between 1998 and 2008 [30].

One of the main findings of the present study is the higher NIV success rate in $2010 / 11$ compared to 2002 and
1997. Many factors may have contributed to this improvement [31], including better patient selection, as suggested by the decreased use of NIV in de novo ARF, a major contributor to NIV failure [7]. Importantly, critical illness severity in patients given NIV did not decrease over time, as shown by the similarity in SAPS II scores and blood gas values in our three studies [6, 7]. Changes in NIV practices and devices may also have contributed to improve NIV success rates. This includes replacement of home ventilators by NIV-dedicated ventilators [32], use of the NIV algorithm [33], and increased use of a face mask or full-face mask instead of a nasal mask [34]. Finally, in a recent study, more widespread use of NIV to treat acute-onchronic respiratory failure was associated with lower NIV failure rates [35], suggesting a learning curve or case-volume effect [36]. The increased use of NIV in our study may have had a similar impact on NIV success rates.

Successful NIV therapy was associated with lower mortality in all categories of ARF, in keeping with earlier data $[6,7,37]$. This finding suggests that the benefits of NIV in randomized controlled trials also occur in unselected patients seen in everyday clinical practice. However, the impact of NIV failure varied across patient groups. NIV failure in acute-on-chronic respiratory failure 
and acute cardiogenic pulmonary edema was not associated with death in excess. Overall, first-line NIV itself was beneficial in these two situations. These results are consistent with reports of successful NIV therapy and good survival rates in patients with acute-on-chronic respiratory failure even with very advanced respiratory acidosis or coma, despite a higher frequency of NIV failure $[38,39]$. In contrast, in patients with de novo ARF, first-line NIV was not associated with decreased mortality, as confirmed in a recent study [18]. Moreover, in 2002, NIV failure in de novo ARF was associated with significantly higher mortality compared to first-line invasive mechanical ventilation [28]. Several randomized controlled trials have demonstrated beneficial effects of NIV in de novo ARF. However, these trials were conducted in highly selected patient subgroups $[2,40]$ such as immunocompromised patients $[4,5,41]$, patients after lung resection $[42,43]$, or selected patients with severe hypoxemic ARF and no hypercapnia [44]. Importantly, in 2010/11 NIV failure was no longer associated with an excess in mortality in patients with de novo ARF. The decline in NIV use in this population suggests a better selection of patients with de novo ARF for NIV therapy. A greater proficiency of staff in administering NIV may also have contributed to the fact that NIV failure did not seem to be harmful in this population anymore.

Finally, ICU mortality decreased over time, which is consistent with recently reported data [15]. This decrease was seen in all categories of ARF but was the largest in de novo ARF. During the same period, declines occurred in mechanical ventilation duration and ICU stay length.

The limitations of our study need to be acknowledged. We may have underestimated NIV hospital use, as we did not include patients who received NIV purely outside the
ICU. However, this was not within the scope of our study that aimed at evaluating NIV conducted in the ICU. The patients were recruited in only two European countries. This, however, allowed us to compare our findings to those from our previous prospective audits, which were performed in France. Finally, although high overlap occurred among the ICUs that participated in the three studies, these ICUs were not exactly the same. It would have been very difficult to conduct three studies over a 14-year period in exactly the same ICUs.

In conclusion, changes in NIV practices and increased use of NIV in French and Belgian ICUs were documented and have resulted in an observed increase in NIV success rates. Although NIV is beneficial overall, the highest failure rates are seen in patients with de novo ARF. Although in 2010/11 NIV failure in de novo ARF was no longer associated with an excess in mortality, this result probably reflects better patient selection, as NIV use in this population was lower than in previous years. Thus, in de novo ARF, NIV should be used with discernment and the need for invasive mechanical ventilation promptly recognized. Studies designed to identify criteria for determining which patients with de novo ARF are likely to benefit from NIV would be welcome.

\section{Complaince with ethical standards}

Conflicts of interest None of the authors declares any conflicts of interest pertaining to this work. Alexandre Demoule has signed research contracts with Covidien, Maquet, and Philips; he has also received personal fees from Covidien. Samir Jaber has received personal fees from Dräger, Fisher and Paykel, Hamilton, and Maquet. Laurent Brochard declares research contracts with Covidien, Dräger, General Electrics, and Vygon and personal fees from Covidien. Élie Azoulay declares research grants from Pfizer and MSD and personal fees from Gilead.

\section{References}

1. Brochard L, Mancebo J, Wysocki M, Lofaso F, Conti G, Rauss A, Simonneau G, Benito S, Gasparetto A, Lemaire F (1995) Noninvasive ventilation for acute exacerbations of chronic obstructive pulmonary disease. N Engl J Med 333:817-822

2. Keenan SP, Sinuff T, Cook DJ, Hill NS (2003) Which patients with acute exacerbation of chronic obstructive pulmonary disease benefit from noninvasive positive-pressure ventilation? A systematic review of the literature. Ann Intern Med 138:861-870

3. Masip J, Roque M, Sanchez B,

Fernandez R, Subirana M, Exposito JA (2005) Noninvasive ventilation in acute cardiogenic pulmonary edema: systematic review and meta-analysis. JAMA 294:3124-3130
4. Hilbert G, Gruson D, Vargas F, Valentino R, Gbikpi-Benissan G, Dupon M, Reiffers J, Cardinaud JP (2001) Noninvasive ventilation in immunosuppressed patients with pulmonary infiltrates, fever, and acute respiratory failure. N Engl J Med 344:481-487

5. Antonelli M, Conti G, Bufi M, Costa MG, Lappa A, Rocco M, Gasparetto A, Meduri GU (2000) Noninvasive ventilation for treatment of acute respiratory failure in patients undergoing solid organ transplantation: a randomized trial. JAMA 283:235-241

6. Carlucci A, Richard JC, Wysocki M, Lepage E, Brochard L (2001) Noninvasive versus conventional mechanical ventilation. An epidemiologic survey. Am J Respir Crit Care Med 163:874-880
7. Demoule A, Girou E, Richard JC, Taille S, Brochard L (2006) Increased use of noninvasive ventilation in French intensive care units. Intensive Care Med 32:1747-1755

8. Park M, Sangean MC, Volpe Mde S, Feltrim MI, Nozawa E, Leite PF, Passos Amato MB, Lorenzi-Filho G (2004)

Randomized, prospective trial of oxygen, continuous positive airway pressure, and bilevel positive airway pressure by face mask in acute cardiogenic pulmonary edema. Crit Care Med 32:2407-2415

9. Giacomini M, Iapichino G, Cigada M, Minuto A, Facchini R, Noto A, Assi E (2003) Short-term noninvasive pressure support ventilation prevents ICU admittance in patients with acute cardiogenic pulmonary edema. Chest $123: 2057-2061$ 
10. Ferrer M, Sellares J, Valencia M, Carrillo A, Gonzalez G, Badia JR, Nicolas JM, Torres A (2009) Noninvasive ventilation after extubation in hypercapnic patients with chronic respiratory disorders: randomised controlled trial. Lancet 374:1082-1088

11. Chiumello D, Chevallard G, Gregoretti C (2011) Non-invasive ventilation in postoperative patients: a systematic review. Intensive Care Med 37:918-929

12. Chiumello D, Coppola S, Froio S, Gregoretti C, Consonni D (2013) Noninvasive ventilation in chest trauma: systematic review and metaanalysis. Intensive Care Med 39:1171-1180

13. Conférence de consensus commune (SRLF-SPLF-SFAR) (2006)

Ventilation non invasive dans l'insuffisnce respiratoire aiguë. Réanimation 6

14. Esteban A, Ferguson ND, Meade MO, Frutos-Vivar F, Apezteguia C, Brochard L, Raymondos K, Nin N, Hurtado J, Tomicic V, Gonzalez M, Elizalde J, Nightingale P, Abroug F, Pelosi P, Arabi Y, Moreno R, Jibaja M, D'Empaire G, Sandi F, Matamis D, Montanez AM, Anzueto A (2008) Evolution of mechanical ventilation in response to clinical research. Am $\mathbf{J}$ Respir Crit Care Med 177:170-177

15. Esteban A, Frutos-Vivar F, Muriel A, Ferguson ND, Penuelas O, Abraira V, Raymondos K, Rios F, Nin N, Apezteguia C, Violi DA, Thille AW, Brochard L, Gonzalez M, Villagomez AJ, Hurtado J, Davies AR, Du B, Maggiore SM, Pelosi P, Soto L, Tomicic V, D'Empaire G, Matamis D, Abroug F, Moreno RP, Soares MA, Arabi Y, Sandi F, Jibaja M, Amin P, Koh Y, Kuiper MA, Bulow HH, Zeggwagh AA, Anzueto A (2013) Evolution of mortality over time in patients receiving mechanical ventilation. Am J Respir Crit Care Med 188:220-230

16. Demoule A, Chevret S, Kouatchet A, Jaber S, Meziani F, Schmidt M, Schnell D, Clergue C, Aboab J, Rabbat A, Lambert D, Guerin C, Georges H, Zuber B, Dellamonica J, Das V, Cousson J, Drault J, Kalfon P, Perez D, Forceville X, Depuyt P, Jacobs F, Legrand M, Lambert J, Castanier M, Brochard L, Azoulay E (2013) Understanding noninvasive mechanical ventilation success in French and Belgian ICUs. Am J Respir Crit Care Med 187:A5724
17. Azoulay E, Kouatchet A, Jaber S, Lambert J, Meziani F, Schmidt M, Schnell D, Mortaza S, Conseil M, Tchenio X, Herbecq P, Andrivet P, Guerot E, Lafabrie A, Perbet S, Camous L, Janssen-Langenstein R, Collet F, Messika J, Legriel S, Fabre X, Guisset O, Touati S, Kilani S, Alves M, Mercat A, Similowski T, Papazian L, Meert AP, Chevret S, Schlemmer B, Brochard L, Demoule A (2013) Noninvasive mechanical ventilation in patients having declined tracheal intubation. Intensive Care Med 39:292-301

18. Schnell D, Timsit JF, Darmon M, Vesin A, Goldgran-Toledano D, Dumenil AS, Garrouste-Orgeas M, Adrie C, Bouadma L, Planquette B, Cohen Y, Schwebel C, Soufir L, Jamali S, Souweine B, Azoulay E (2014) Noninvasive mechanical ventilation in acute respiratory failure: trends in use and outcomes. Intensive Care Med 40:582-591

19. Le Gall JR, Lemeshow S, Saulnier F (1993) A new Simplified Acute Physiology Score (SAPS II) based on a European/North American multicenter study. JAMA 270:2957-2963

20. Curtis JR, Cook DJ, Sinuff T, White DB, Hill N, Keenan SP, Benditt JO, Kacmarek R, Kirchhoff KT, Levy MM (2007) Noninvasive positive pressure ventilation in critical and palliative care settings: understanding the goals of therapy. Crit Care Med 35:932-939

21. Azoulay E, Kouatchet A, Jaber S, Meziani F, Papazian L, Brochard L, Demoule A (2013) Non-invasive ventilation for end-of-life oncology patients. Lancet Oncol 14:e200-e201

22. Esteban A, Anzueto A, Alia I, Gordo F, Apezteguia C, Palizas F, Cide D, Goldwaser R, Soto L, Bugedo G, Rodrigo C, Pimentel J, Raimondi G, Tobin MJ (2000) How is mechanical ventilation employed in the intensive care unit? An international utilization review. Am J Respir Crit Care Med 161:1450-1458

23. Esteban A, Frutos-Vivar F, Ferguson ND, Meade MO, Anzueto A, Brochard L, Alia I, Nightingale P, Pelosi P, D'Empaire G, Arabi Y, Abroug F, Apezteguia C, Tomicic V, Nin N, Tejerina E, Turan G, Gonzalez M, Hurtado J, Raymondos K, David CM (2006) Evaluation in the use of noninvasive ventilation in the ICU. Proc Am Thorac Soc 3:A472

24. Thys F, Roeseler J, Reynaert M, Liistro G, Rodenstein DO (2002) Noninvasive ventilation for acute respiratory failure: a prospective randomised placebocontrolled trial. Eur Respir J $20: 545-555$
25. Wood KA, Lewis L, Von Harz B, Kollef MH (1998) The use of noninvasive positive pressure ventilation in the emergency department: results of a randomized clinical trial. Chest 113:1339-1346

26. L'Her E, Duquesne F, Girou E, de Rosiere XD, Le Conte P, Renault S, Allamy JP, Boles JM (2004)

Noninvasive continuous positive airway pressure in elderly cardiogenic pulmonary edema patients. Intensive Care Med 30:882-888

27. Vaschetto R, Turucz E, Dellapiazza F, Guido S, Colombo D, Cammarota G, Della Corte F, Antonelli M, Navalesi P (2012) Noninvasive ventilation after early extubation in patients recovering from hypoxemic acute respiratory failure: a single-centre feasibility study. Intensive Care Med 38:1599-1606

28. Demoule A, Girou E, Richard JC, Taille $\mathrm{S}$, Brochard L (2006) Benefits and risks of success or failure of noninvasive ventilation. Intensive Care Med 32:1756-1765

29. Evans TW (2001) International Consensus Conferences in Intensive Care Medicine: non-invasive positive pressure ventilation in acute respiratory failure. Intensive Care Med 27:166-178

30. Funk GC, Bauer P, Burghuber OC, Fazekas A, Hartl S, Hochrieser H, Schmutz R, Metnitz P (2013) Prevalence and prognosis of COPD in critically ill patients between 1998 and 2008. Eur Respir J 41:792-799

31. Ozyilmaz E, Ugurlu AO, Nava S (2014) Timing of noninvasive ventilation failure: causes, risk factors, and potential remedies. BMC Pulm Med 14:19

32. Carteaux G, Lyazidi A, CordobaIzquierdo A, Vignaux L, Jolliet P, Thille AW, Richard JC, Brochard L (2012) Patient-ventilator asynchrony during noninvasive ventilation: a bench and clinical study. Chest 142:367-376

33. Vignaux L, Tassaux D, Jolliet P (2007) Performance of noninvasive ventilation modes on ICU ventilators during pressure support: a bench model study. Intensive Care Med 33:1444-1451

34. Olivieri C, Costa R, Spinazzola G, Ferrone G, Longhini F, Cammarota G, Conti G, Navalesi P (2013) Bench comparative evaluation of a new generation and standard helmet for delivering non-invasive ventilation. Intensive Care Med 39:734-738 
35. Chandra D, Stamm JA, Taylor B, Ramos RM, Satterwhite L, Krishnan JA, Mannino D, Sciurba FC, Holguin F (2012) Outcomes of noninvasive ventilation for acute exacerbations of chronic obstructive pulmonary disease in the United States, 1998-2008. Am J Respir Crit Care Med 185:152-159

36. Dres M, Tran TC, Aegerter P, Rabbat A, Guidet B, Huchon G, Roche N (2013) Influence of ICU case-volume on the management and hospital outcomes of acute exacerbations of chronic obstructive pulmonary disease. Crit Care Med 41:1884-1892

37. Esteban A, Anzueto A, Frutos F, Alia I, Brochard L, Stewart TE, Benito S, Epstein SK, Apezteguia C, Nightingale $\mathrm{P}$, Arroliga AC, Tobin MJ (2002) Characteristics and outcomes in adult patients receiving mechanical ventilation: a 28 -day international study. JAMA 287:345-355
38. Conti G, Antonelli M, Navalesi P, Rocco M, Bufi M, Spadetta G, Meduri GU (2002) Noninvasive vs. conventional mechanical ventilation in patients with chronic obstructive pulmonary disease after failure of medical treatment in the ward: a randomized trial. Intensive Care Med 28:1701-1707

39. Diaz GG, Alcaraz AC, Talavera JC, Perez PJ, Rodriguez AE, Cordoba FG, Hill NS (2005) Noninvasive positivepressure ventilation to treat hypercapnic coma secondary to respiratory failure. Chest 127:952-960

40. Antonelli M, Conti G, Bello G (2013) New niches for NIV: ahead with caution! Intensive Care Med 39:1325-1327

41. Azoulay E, Lemiale V, Mokart D, Pene F, Kouatchet A, Perez P, Vincent F, Mayaux J, Benoit D, Bruneel F, Meert AP, Nyunga M, Rabbat A, Darmon M (2014) Acute respiratory distress syndrome in patients with malignancies. Intensive Care Med 40:1106-1114
42. Auriant I, Jallot A, Herve P, Cerrina J, Le Roy Ladurie F, Fournier JL, Lescot B, Parquin F (2001) Noninvasive ventilation reduces mortality in acute respiratory failure following lung resection. Am J Respir Crit Care Med 164:1231-1235

43. Lorut C, Lefebvre A, Planquette B, Quinquis L, Clavier H, Santelmo N, Abou Hanna H, Bellenot F, Regnard JF, Riquet M, Magdeleinat P, Meyer G, Roche N, Huchon G, Coste J, Rabbat A (2014) Early postoperative prophylactic noninvasive ventilation after major lung resection in COPD patients: a randomized controlled trial. Intensive Care Med 40:220-227

44. Ferrer M, Esquinas A, Leon M, Gonzalez G, Alarcon A, Torres A (2003) Noninvasive ventilation in severe hypoxemic respiratory failure: a randomized clinical trial. Am J Respir Crit Care Med 168:1438-1444 